editorial

1 Diabetiker mit KHK nach der FREEDOM-Studie

Bypass oder $\mathrm{PCI}$ ?

H. Holzgreve, München

aufgefallen

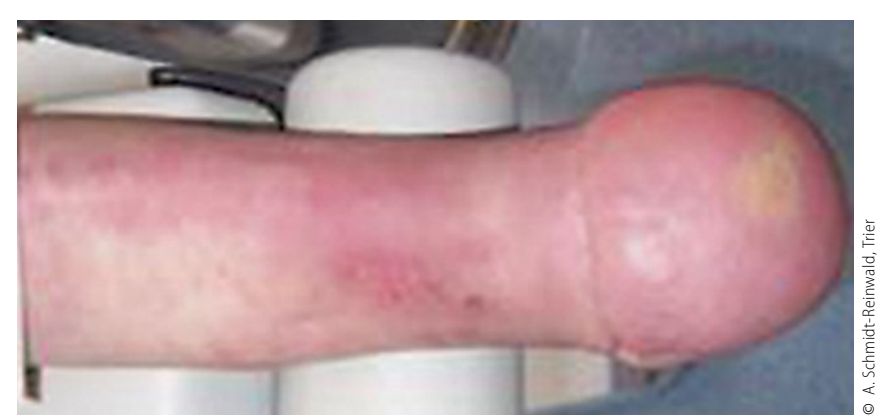

4 Diabetischer Fuß

Charcot-Verdacht rettet Unterschenkel

A. Schmidt-Reinwald, Trier

journal screen

6 Übersicht der referierten Studien

zertifizierte fortbildung

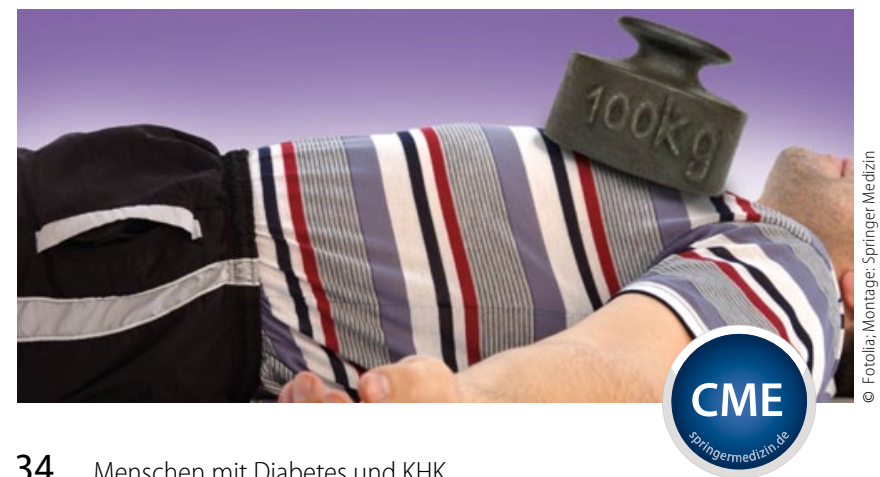

34 Menschen mit Diabetes und KHK

Besonderheiten der Herzinfarkttherapie

W. Motz und W. Kerner, Karlsburg

39 CME Fragen

Besonderheiten der Herzinfarkttherapie fortbildung

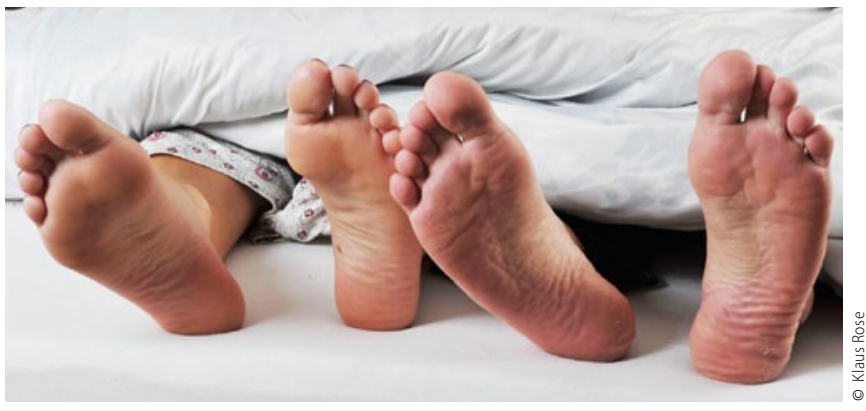

41

Erektile Dysfunktion, Anorgasmie

Die häufigsten Sexualstörungen bei Diabetikern

L. Schaaf, München

aktuell

45 Bericht US-Nephrologen-Kongress

Diabetikerniere im Fokus

46 Kongressbericht EASD-Jahrestagung

Diabetes, Insulin und Krebs

47 Stets auf dem neuesten Stand

e.Med: die e.News

rubriken

$50 \quad \ln \mid$ Fo|Pharm

57 Editorial Board | Impressum | Kontakt

Beihefter/Beilagen

\section{Medizinreport aktuell}

GLP-1-Agonisten - Früher Einsatz von Liraglutid steigert den Therapieerfolg (S. 48)

\section{Pharmawissen aktuell (Beilagen)}

SGLT-2-Hemmung: Insulinunabhängige Therapieoption

Therapie des Typ-2-Diabetes: Sitagliptin - ein DPP-4-Hemmer mit breitem Anwendungsspektrum 